\title{
Systematically Mapping Connection between Rapid Automatized Naming Task and Reading Performance: A Meta-analysis of Correlational Data
}

\author{
Eugene Borokhovski*, Robert M. Bernard, Norman Segalowitz, Anna Sokolovskaya \\ Concordia University, Montreal, Canada \\ *Correspondence author. E-mail: eborokhovski@education.concordia.ca
}

\begin{abstract}
Introduction. This meta-analytical study of primary research on early literacy explores and summarizes patterns of correlation between performance on Rapid Automatized Naming (RAN) task and measures of specific reading skills. This is the first large-scale meta-analysis intended to verify claims of the double-deficit hypothesis of relative independence of naming speed and phonological awareness factors in developmental dyslexia and to systematically map specific connection between RAN performance and various literacy competencies.
\end{abstract}

Method. Two-hundred-forty-one primary studies identified through systematic searches of related empirical literature yielded 1551 effect sizes of two types - crosssectional (correlations at the same time) and longitudinal (when measures of RAN and reading were considerably separated in time), reflecting RAN-to-reading correlations for seven independent outcome types.

Results. The overall weighted average effect sizes were: $r^{+}=314, k=1254$ and $r^{+}=343$, $k=297$, respectively. Subsequent moderator variable analyses further explored RAN-toreading associations dependent on RAN type, particular reading skills, age of learners and other factors. Among the strongest and most consistent in both sub-collections were correlation between symbolic RAN and reading speed and between non-symbolic RAN and reading comprehension, whereas both RAN types were strongly associated with decoding skills and reading composite measures.

Discussion. Patterns of RAN-to-reading correlation provided insufficient support for the double-deficit hypothesis, but were suggestive of perceiving RAN as a measure of "pre-reading" skills, an "equal among equals" correlate of reading performance. The study also emphasizes the important role of both automatic and controlled cognitive processes for successful RAN task performance in its connection to reading competency.

\section{Keywords}

meta-analysis, Rapid Automatized Naming, reading outcomes, degree of association, early literacy, developmental dyslexia, double-deficit hypothesis, phonological awareness, automatic processes, controlled processes 


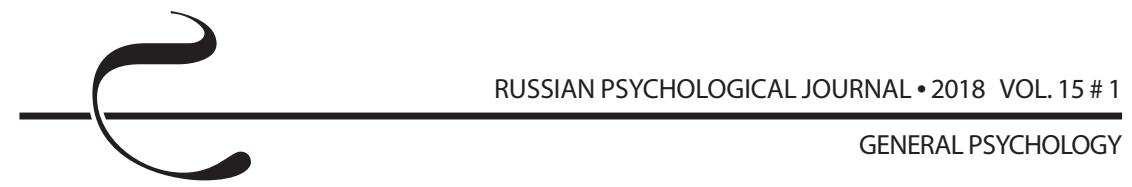

\section{Highlights}

- A meta-analysis of correlational (cross-sectional and longitudinal) research summarized empirical data on degree of association between Rapid Automatized Naming (RAN) scores and principal reading outcomes and found low-to-moderate positive average effect size, heterogeneous, but fairly compatible across levels of moderator variables.

- Symbolic RAN task performance produced stronger correlations with measures of reading speed, decoding skills and reading composites persisted across study designs, age groups and population types.

- Non-symbolic RAN, though on average produced weaker connected to reading performance, nevertheless showed relatively strong and consistent correlations with the measures of reading comprehension.

- Higher consistency of patterns of correlations between RAN and reading in longitudinal data may suggest that the task usage for prognosis of future reading performance is more reliable than for the purposes of diagnosing current deficiencies.

- The role of controlled cognitive processes (management of attentional resources) in underlying RAN performance appears to be somewhat underestimated.

\section{For citation}

Borokhovski E., Bernard R.M., Segalowitz N., Sokolovskaya A. Systematically Mapping Connection between Rapid Automatized Naming Task and Reading Performance: A Metaanalysis of Correlational Data. Rossiiskii psikhologicheskii zhurnal - Russian Psychological Journal, 2018, V. 15, no. 1, pp. 46-76. DOI: 10.21702/rpj.2018.1.3

Original manuscript received 12.02.2018

\section{Introduction}

\section{Study Background, Rationale and Objectives}

In modern society, literacy is nearly always the very first necessary step towards most of further academic and everyday accomplishments, while problems that struggling readers face tend to accumulate and eventually may lead to lifelong professional barriers and social complications. Psychologists and educators increasingly recognize importance of reading as a fundamental competency and continue studying it closely in order to determine who may be at risk of developing reading problems and why, and to devise effective ways to help.

\section{Research of reading deficiencies focus on developmental dyslexia}

So-called developmental dyslexia occupies a special place among various reading impairments, primarily because no obvious definite reason is readily available to account for problems with reading performance. Consider, for instance, the classic consensus documented by M. Critchley [1]: "[Developmental dyslexia is] ... 
a disorder manifested in difficulty in learning to read despite conventional instruction, adequate intelligence and socio-cultural opportunity" (cited by [2], p. 15). This definition is but one of earlier examples in a vast collection of similar approaches to the problem including, those by $[3,4,5]$, among many others. These definitions not only distinguish developmental dyslexia from other forms of learning disabilities, but also emphasize that the phenomenon derives from problems in cognitive development and is not associated with any particular intellectual setbacks or any form of social or educational deprivation.

Various conceptual and diagnostic models focus on the issue of developmental dyslexia. Addressing them in detail is beyond the scope of this paper. Here, it would suffice to say that the vast majority of theories and educational practices tend to emphasize the fundamental role of phonological awareness in proper development of reading skills. Phonological awareness is understood as individual's ability to understand and efficiently handle the relationships that exist between graphemes and phonemes as elements of written and spoken language respectively. Long line of psychological, linguistic and pedagogical research has repeatedly demonstrated that phonological awareness is among the strongest and most reliable predictors for successful development of reading skills in children [e. g., 2, 6, 7, 8, 9, 10, 11]. The existence of a phonological core deficit in developmental dyslexia has been strongly supported by research not only on children, but on adult struggling readers, as well [e. g., 12]. In addition, pedagogical interventions especially designed to provide training in phonological skills appear to be quite successful in improving reading outcomes [e. g., 13, 14, 15]. There are also empirical data, from languages other than English, that demonstrate similarly strong relationships between phonological awareness and reading performance - for example, in Chinese [16, 17], in Dutch [18], and in German [19], though the high grapheme-phoneme consistency of German orthography helps children to overcome phonology-based reading deficiencies more easily. Bilinguals have shown comparable patterns of results with respect to the role of phonological awareness in their reading performance (e. g., [20] - in French / English bilinguals; [21] - in Herero (Namibian) / English bilinguals; [22] - in Dutch / English bilinguals).

In light of all these findings a discussion in the literature somewhat shifts towards addressing a related question of whether the phonological core deficit alone provides sufficient explanation for manifestations of developmental dyslexia or other factors may play compatibly important role in the same class of reading impairments.

\section{Double-deficit hypothesis in reading research}

M. Wolf and P.G. Bowers [23], the authors of the so-called double-deficit hypothesis, argue against limiting explanations for developmental dyslexia to 


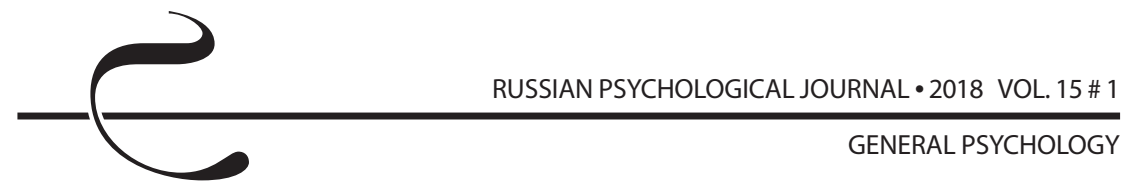

phonological deficit. Their research emphasizes the role of the second factor naming speed - as another major contributor to skilled reading that is relatively independent from phonological awareness. Naming speed, typically measured by the Rapid Automatized Naming (RAN) task, is the ability for speeded naming of large sequences of simple stimuli aloud. According to the double-deficit hypothesis, the most severe cases of developmental dyslexia occur when both phonological awareness and naming speed are impaired the same time in a child's cognitive profile.

In brief, the key attributes of the double-deficit hypothesis are:

1. Cognitive deficit that is different from the core phonological deficit a naming speed deficit - is also responsible for difficulties in reading development.

2. It is relatively independence from the phonological awareness deficit (implying to an extent some substantial differences between the two in their underlying cognitive mechanisms).

3. When both deficits are combined in the same person, their cumulative negative effect on reading outcomes is especially severe.

This section provides just a few examples of the research evidence on the last point - the increasingly negative impact on reading resulting from the double-deficit. M.W. Lovett, K. A. Steinbach, and J.C. Frijters [24] documented the most troubling cases of developmental dyslexia in those of their participants who were classified as having both deficits. According to [25], clearly noticeable difficulties on a wide range of reading tasks were observed in a subgroup of second graders diagnosed with the double-deficit, but not in groups with only a single deficit. In a study of 251 Spanish-speaking young learners of English, F. R. Manis, K. A. Lindsey, and C.E. Bailey [26] demonstrated that both factors (phonological awareness and naming speed) underlying reading disabilities in monolingual children may be equally important for understanding difficulties in learning to read in a second language. Among other studies reporting findings generally in support of the double-deficit hypothesis could be named also [27, 28, 29, 30, 31,32 ] and a number of others (please, see [33] for a review). The importance of phonological awareness and naming was also demonstrated in studies designed to evaluate the effectiveness of different instructional interventions in reading. For example, E.A. Harn [34] reported that kindergarten students with the double-deficit were less responsive to any of three seven-month programs of special instructions in reading. Also, among the three, the most systematic program (the one that systematically addressed skills in each impaired domain) was also the most successful.

There have been other reports regarding the joint effect of both deficits in people with severely impaired reading. J. Nopola-Hemmi et al. [35] analyzed the neurological data of 24 dyslexics from a three-generation Finnish family. They 
established that in all of them the phonological awareness deficit was accompanied by a naming speed deficit, as well as by problems with short-term verbal memory. Cluster analysis of several subtypes of developmental dyslexia, undertaken by J.M. Fletcher et al. [36], revealed that in four out of five such subtypes phonological awareness was the major common factor coinciding with either slower naming speed or somewhat impaired verbal short-term memory. In another piece of research, R.D. Tiu, S. J. Wadsworth, R. K. Olson, and J. C. DeFries [37] investigated genetic and environmental factors in reading disabilities on a large sample of twins drawn from the Colorado Learning Disabilities Research Center database. They concluded that both phonological awareness and naming speed contributed to impairment in reading and both should therefore be included into any comprehensive model of developmental dyslexia.

In brief, the major idea here is that two deficits, even if each single one of them does not cause serious problems with reading per se, can together create a severe overload of the reading-related cognition system, which is difficult to compensate for.

It is, probably, worth mentioning that some researchers are rather cautious in fully accepting this explanation. For example, C. Schatschneider, C.D. Carlson, D. J. Francis, B. R. Foorman, and J.M. Fletcher [38] argued that severity of reading problems in the double-deficit subgroup of participants could be actually explained in terms of a statistical artifact. Results of their study, indeed, demonstrated that when measures of phonological awareness and naming speed are positively correlated (which is often the case - even if this correlation is not significant), participants categorized into a double-deficit subgroup inevitably represent worse performers on either measure and subsequently, showing poorer reading outcomes.

As impressive as it is, the evidence in favor of the double-deficit hypothesis is not absolutely indisputable. For example, P.T. Ackerman, C. A. Holloway, P. L. Youngdahl and R.A. Dykman [39] did not find any markedly impaired reading performance in their sample of dyslexics with a double-deficit profile compared to subgroups with a single deficit. Moreover, all poor readers, in addition to having compromised phonological awareness and naming speed skill, also demonstrated problems with orthographic tasks, attention, arithmetic, and nearly all WISC-III (Wechsler Intelligence Scale for Children, the Third Edition - e. g., [40]) subtasks leading the authors to propose a "multiple causality theory" of developmental dyslexia.

In summary, possible reservations aside, phonological awareness deficits and the naming speed deficits are broadly recognized to be among the major cognitive factors underlying developmental dyslexia as their respective measures are shown to be quite strong correlates of reading achievements, especially in younger readers. In the subsequent section we consider more closely the lesser 


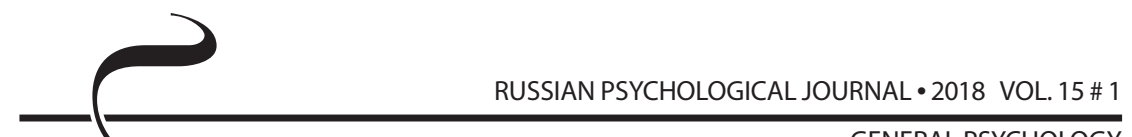

GENERAL PSYCHOLOGY

established factor - the naming speed - how it is operationalized and measured in applied research, and what findings have been obtained with regard to its connection to reading performance.

\section{Rapid Automatized Naming (RAN) task and reading}

Like phonological awareness, naming speed also has rather a long and rich research history. Originally proposed by N. Geschwind [41, 42] and then tested by M. B. Denckla [43], the idea was that cognitive factors (their speed and efficiency that is) involved in attaching a verbal label to an abstract visual category (e. g., basic colors) might well predict future reading performance. This idea eventually resulted in the design of the Rapid Automatized Naming (RAN) task [44]. That test has now become the prototype for many subsequent versions broadly used as naming speed assessment tools in research fields of cognitive development, education and educational psychology and has even been included in some standard screening procedures for early diagnoses of reading disorders [e. g., 45, $46,47]$.

The typical RAN task is composed of four sub-tasks in which participants are required to name aloud as quickly as possible a large sequence of either symbolic (letters, numbers) or non-symbolic (colors, pictures of common objects) stimuli presented in a $5 \times 10$ (five rows of ten characters per each) display, either on $A 4$ white paper sheet or on a computer screen. Since the initial introduction of the RAN task, a multitude of studies have demonstrated a strong connection between participants' performance on different types, versions, and subtasks of RAN and their reading abilities. In brief, the faster RAN task performance, the more favorable prognosis for competent reading development. Here is a brief overview of this line of research.

During the past three decades, the connection between RAN task performance and reading has been empirically studied cross-sectionally, longitudinally, and in across-language studies. Cross-sectional studies have addressed the question how well RAN task performance distinguishes developmental dyslexia from other learning disabilities that are not reading-specific. Longitudinal studies have used RAN task performance in earlier stages of cognitive development as a predictor of reading outcomes later on in different age groups. Finally, acrosslanguage studies have looked at the relationships between measures of RAN task performance and reading fluency in different languages.

Some of the most relevant and illustrative cross-sectional and longitudinal studies involving RAN show that dyslexics, and poor readers in general, perform much worse on practically all RAN and RAN-like subtasks than do age-matched average readers and, importantly, people with other than reading-specific learning disabilities [e. g., 18, 44, 48, 49, 50, 51]. They also show that naming 
speed, as measured by different versions of the RAN task is strongly associated with different aspects of reading skills across age groups and can be useful in predicting success of instructional intervention in reading [e. g., 30, 52, 53, 54, $55,56,57,58,59]$.

In particular, P.T. Ackerman and R.A. Dykman [60], while testing a sample of 7-12 year-olds, found that RAN task performance distinguished dyslexics from both slower learners and those diagnosed with Attention Deficit Disorder. According to [43], dyslexic children are more than one standard deviation below kindergarten norm on naming colors. Similarly, N. A. Badian [61, 62] showed that RAN performance on all subtests - colors, objects, digits and letters - correlates with later reading achievements. In addition, it is worth noting again that, according to the double-deficit hypothesis [23], naming speed contributes to reading not only significantly, but also independently from phonological awareness. Several studies have examined the RAN task's predictive power when the factor of phonological awareness was first statistically accounted for. A. Cornwall [63] reported RAN's unique share in variance of reading among other factors such as phonological awareness and verbal memory. In [51], RAN task performance was one of best individual predictors of reading abilities, clearly differentiating impaired from normal readers. According to [64], digit-naming speed contributed a unique portion of variance in reading speed scores. The list of relevant examples goes on, though not all of the research unequivocally demonstrates that RAN task performance is uniquely linked to the development and manifestation of reading skills.

One interesting source of variation in the relationship between RAN task performance and reading skill is the language in which the tests are given. The more transparent the language grapheme-phoneme structure is (i. e., the more word pronunciation directly matches spelling), the more closely RAN task performance is associated with reading (better predicts it). This kind of regularity has been observed and documented in Dutch [e. g., 18, 65, 66, 67], though [68] reported no particular difference between English and Dutch in the relative predictive power of phonological awareness and naming speed measures; in Finnish [e. g., 69, 70, 71]; in German [e. 9., 19, 59, 72, 73, 74, 75], though [76] acknowledged the leading role of phonological awareness deficits in comparison with the naming speed deficits in reading impairments in German; in Spanish [e. g., 77, 78], though [26] suggested that in bilinguals, some cognitive factors, like phonological awareness, function across languages, whereas other, like naming speed appear to be stronger reading correlates within a given individual language; and in Russian [e. g., 79] where it was shown that while phonological awareness remained the strongest predictor of basic reading skills in English, naming speed played that role for Russian in Russian-English bilinguals in first and second graders. 


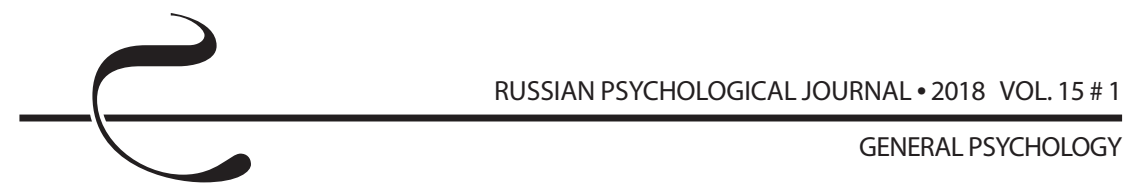

As it is emphasized in [80], greater orthographic regularity in more transparent languages reduces the demand for phonological analysis. Almost echoing this remark, K. Landerl [19] suggested that although a phonological awareness deficit still could be the core deficit in German poor readers, the high consistency of German orthography might just make it easier for learners to overcome the problem. To complete the picture, there is also the notion that phonological skills, especially in the more transparent languages, could be a function of literacy exposure and experience in reading [81]. Under such circumstances, naming speed, as measured by RAN task performance, overtakes phonological awareness as a leading predictor of reading outcomes. This observation may also be important as an argument in favor of relatively independent nature of naming speed within the whole set of cognitive factors that contribute to successful reading acquisition.

In fairness, some researchers exercised caution when interpreting RANrelated findings. As noted earlier, high severity of dyslexia symptoms in people with a double-deficit could be attributed to a statistical artefact [38] that masks individual contribution of each factor to the overall reading impairment. In addition, the central assumption of the double-deficit hypothesis, that naming speed is independent from the cognitive processes responsible for phonological awareness, has been periodically questioned in the literature. In several studies phonological awareness and naming speed came out to be correlated significantly above chance or showed other signs of interdependence [e. g., 31, 82, 83, 84, 85].

Finally, not all longitudinal and special population studies have yielded equally conclusive evidence regarding the predictive power of the RAN task. For example, A.G. Bishop [86] found a model that combined measures of letter identification, phonological awareness, and naming speed to be the best of five tested predictive models of early reading development, whereas [87] reported no direct relationship between RAN task performance and a level of reading achievements. J. Holland, D. McIntosh, and L. Huffman [88] emphasized the role of orthographic processing rather than either phonology or naming speed in their participants' decoding skills. See also $[89,90,91]$ for some other predictive or path-analyses models involving RAN. Yet other studies appeared to have some design problems that prevented separating reading difficulties from other co-occurring developmental problems, making it complicated to draw any firm interpretations of findings (see [92], for review).

Notwithstanding these controversies, research to date has rather convincingly demonstrated naming speed, as measured by performance on the RAN task, to be one of two major factors underlying development of reading. The overall impression from reviews of relevant research is that the empirical evidence predominantly supports the existence (well beyond chance) of association between RAN task performance and the measures of reading skills. The strength of this 
association, however, varies substantially across studies. Here are a few examples from studies mentioned in this section. Individual coefficients of correlation range from about virtually negligible (P.G. Bowers and L. B. Swanson [93]: $r=0.02-$ between digit naming and a measure of decoding skills or A.S. Chandarina [79]: $r=0.03$ - between letter naming and vocabulary knowledge) to extraordinary high (G. K. Deutsch et al. [94]: $r=0.87$ or V.W. Berninger, C. Yates and K. Lester [95]: $r=0.71$ - both between letter naming and measures of single word reading efficiency). In other words, the degree of the RAN-to-reading correlation is highly heterogeneous and presumably depends on many factors including, among others, particular measures of either naming speed or reading skills, participants' age, language and degree of proficiency/impairment in reading.

Some, even preliminary/basic, closure is definitely in order in our understanding of the structure and the moderating effects of major demographic study features on the degree of association among different types of RAN-task and various measures of reading competency. As such, two major research questions for the present study could be stated as follows:

1. What is the point estimate of the degree of association between the RAN task and reading?

2. What factors affect the strength of this association and to what extent?

These questions are addressed here by means of a large-scale meta-analysis of available correlational data.

\section{Present Study}

The method of meta-analysis, employed by the present study, shows whether a general effect (the above chance correlation between variables in question - in this case between measures of Ran-task performance and reading skills) exists consistently across numerous relevant studies and what its overall magnitude is. Moreover, it allows for exploring sources of variability in the effect sizes through analyses of methodological, substantive, and demographic study features as they mediate/moderate the strength of association between RAN and reading. Given a great deal of controversy surrounding research findings concerning the RAN task [e. g., 92], a meta-analysis also appears to be the most potent tool to use in an attempt to reconcile such data.

\section{What is known and still unclear from the earlier meta-analyses?}

Previously, a couple of meta-analyses investigated various correlates of reading and reported significant low-to-moderate correlations between RAN and different aspects of reading [96, 97]. In some cases, the RAN task even seemed to slightly overshadow indices of phonological awareness. Interpreting these findings, D.D. Hammill [96] made two interesting points. 
First, it was noticed that the variables most highly correlated with reading could be classified in so-called "print clusters" (e. g., alphabet knowledge, single phoneme-letter recognition, print awareness), as they are related to the English writing system and typically acquired through formal education. The "non-print clusters" (including RAN and phonological awareness, alongside with memory, spoken language, perceptual and motor skills) combines more general cognitive abilities that are less strongly correlated with reading. Second, from an applied perspective, the author concluded that, despite their significant correlation with reading, variables in the non-print cluster might be overemphasized in the research literature. Thus, the regular educational practice should refocus attention from these skills onto more trainable abilities in written language which are closer connected to reading and involve processing of printed text. The last suggestion, as practical as it may seem, neither helps much in understanding the cognitive nature of the RAN-to-reading association nor addresses the needs of those (3-5\%) children who are less responsive to formal reading instruction, presumably because of some deeper (rooted in cognitive development) shortcomings.

However, there are issues that remain largely unaddressed. For example, none of the meta-analyses above treated the language on which participants performed either RAN or reading tasks as a substantive study feature, leaving no opportunity to verify M. Wolf et al. [33] claim that in more transparent (in terms of grapheme-to-phoneme correspondence) the RAN task outperforms measures of phonological awareness as a predictor of reading outcomes. There are other factors that definitely deserve special attention, including type of the RAN (i. e., symbolic vs. non-symbolic) and reading (i. e., specific skills and competencies speed, vocabulary, comprehension, etc.) tasks, as well as participants' age, reading abilities, other substantive and demographic variables.

\section{Research objectives}

Though the previous meta-analyses provide some answers about the overall magnitude of RAN task performance correlations with reading, they have serious limitations. For one, they lack specificity in defining the RAN measure itself; RAN appears there as a single construct, as if there were no differences between symbolic and non-symbolic RAN subtasks. Another limitation is the choice of moderator variables. Some study features, omitted in these meta-analyses, could shed light on the cognitive nature of RAN-to-reading association, not to mention advance our knowledge about conditions under which the strength of this association manifests itself more saliently.

Among study features to consider are those related to the following issues repeatedly emerging in the empirical research. What is the difference between symbolic and non-symbolic RAN subtasks in their association with different aspects 
of reading? [e. g., 61, 67, 80, 98]. What is the optimal timeframe for administering the RAN task? [e. g., 99]. How does the strength of association between RAN and reading change with participants' age and reading abilities? [e. g., 80, 100]. Does the transparency of the grapheme-phoneme language structure influence the degree of RAN-to-reading association? [e. g., 33, 59]. These questions restated into some sort of working hypotheses in favor of: (1) symbolic (i. e., letters and digits) RAN subtasks; (2) younger and less skilled in reading participants: and (3) more transparent with respect to grapheme-phoneme correspondence languages (e. g., Spanish, Russian) guided the current review of two large categories of primary research - studies of cross-sectional or concurrent design (i. e., where RAN performance and reading competencies are assessed within the same time frame) and studies of "longitudinal" or split-time design (i. e., where measures of RAN performance taken at one point in time are expected to predict reading performance later on). These correlational data (respective measures of strength of association between RAN and reading) are meta-analyzed, examined for moderator variables and discussed here.

\section{Method}

\section{Methodology of meta-analysis}

Meta-analysis is a systematic synthesis of quantitative results from the entire collection of primary empirical studies that address the same research question or a set of closely related questions, usually of some applied value [e. g., 101, 102]. Meta-analyses quantify results by extracting from individual studies a standardized metric, called effect size. Individual effect sizes (necessarily independent both with respect to the samples they are derived from and the outcome type they represent) then are aggregated into a single point estimate to reflect either the impact of the treatment (i. e., standardized mean difference between an experimental and a control conditions in "intervention" experimental studies) or the strength of association between variables in question (i. e., correlation coefficients in correlational studies). The latter type of meta-analysis is employed by this project. It systematically follows the set of interrelated procedures that are briefly outlined below (for more detailed guidelines on implementing a typical meta-analytical research, please, see [102, 103, 104, 105].

\section{Search strategy}

The search strategy targeted studies containing in abstracts or descriptive field of the corresponding databases any of the following key terms: "RAN", "rapid naming", "automatized naming", "serial naming", "naming speed" in conjunction with any of the reading-related terms: "literacy", "read*", "dyslex". The timeframe for searches was set from 1976 with no upper limit. 


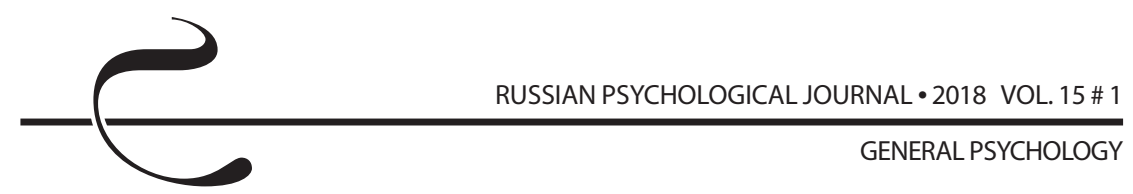

Four electronic databases were consulted because of their expected highest relevance to the research questions: PSYCInfo, PubMed, ERIC, and ProQuest Dissertations and Theses. These searches originally resulted in 1503 hits. Removing duplicates reduced this number to 714 . Also, the bibliographies of reviews, previous meta-analyses, and major empirical studies in the field were scanned resulting in an addition of 21 research articles. At the final stage of the project all searches were updated yielding another 105 sources. Thus, 840 studies in total emerged on the stage of literature searches. They represented both types of studies in the focus of interest for the current project - what we will call cross-sectional (same time correlations between RAN and reading) and longitudinal (RAN measures taken at one point in time correlated with later reading performance).

\section{Inclusion criteria and the review procedure}

Each study identified through literature searches was first reviewed at the abstract level by two coders working independently, who then met to discuss and resolve disagreements and to document the inter-rater reliability rate. Full-text document retrieval was warranted if the study abstract met the following criteria:

- Contains any of the "naming speed" measures using any version (original or modified) of the RAN tasks.

- Reports any measure of participants' reading performance.

- Belongs to a broad category of primary empirical research employing crosssectional or longitudinal design and reports correlational data relating RAN and reading performance.

The procedure for the review of full-text documents followed the very same approach.

Inter-rater agreement rate at both stages of the review was calculated as a percentage of studies, with respect to which both coders agreed whether to reject the study or to continue analyzes and expressed as Cohen's kappa. The extent of uniformity between coders on the subsequent stages of effect size extraction and study features coding was also assessed and documented.

\section{Effect size extraction}

Pearson product-moment correlation coefficients between the measures of RAN and reading performance, weighted by the corresponding sample sizes, as outlined in [106] were analyzed using Comprehensive Meta-Analyses 2.0 software package [107]. This produced an average point estimate (random effects model) separately for cross-sectional and longitudinal studies, and these estimates were further investigated in subsequent moderator variable analyses (mixed model) based on the coded study features. The total $Q$-statistic (fixed effect model) was used to test for homogeneity of the effect size distributions [108]. 


\section{Study features coding}

In order to explore variability in effect sizes, study features (i. e., study design and demographic characteristics of hypothesized importance for explaining the corresponding outcomes) were coded and assessed in a series of moderator analyses. These analyses were of the utmost interest for the project as they addressed the question about factors consistently affecting the degree of association between RAN and reading. The following study features were coded as follows and analyzed.

- Type of the RAN task: symbolic (e. g., letters and digits) and non-symbolic (e. g., objects and colors).

- Type of the reading performance measure: decoding skills, word reading, reading rate, reading comprehension, vocabulary knowledge, spelling, and orthographic skills (for more detailed references to the respective assessment tools, please, see [109].

- A resulting combination of a particular RAN subtask with an individual measure of reading.

- Participants' age, reading and learning abilities, and dominant language.

- The amount of time that passed between the administration of the RAN task and the reading assessment (only applied to the longitudinal studies).

- The moderator variable analyses, in addition to estimating magnitude of the effects in different categories of study features, focused on searching for most coherent (homogeneous) datasets as being more reflective of the corresponding regularities in the respective populations.

\section{Results}

Literature searches revealed 840 individual documents potentially suitable for further examination. Judging from the review of abstracts, 370 studies were marked for retrieval, of which 241 studies were retained after the full-text review for all subsequent analyses. The list of all studies included in this meta-analysis is available from the authors by request. Inter-rater agreement rates at different stages of the review were:

- Abstract review $-92.65 \%$ (Cohen's $\kappa=0.85$ ).

- Full-text review $-93.33 \%$ (Cohen's $\kappa=0.87$ ).

- Agreement rate on the number and selection of the effect sizes $-93.18 \%$ (Cohen's $\kappa=0.86$ ).

- Agreement rate on study features coding $-89.09 \%(\kappa=0.78)$.

The 241 studies produced in total 1254 independent effect sizes in the category of studies that used cross-sectional design, and 297 independent effect sizes in the category of longitudinal studies. Summary statistics for each of the sub-collections are presented in Table 1 and Table 2, respectively. 
Table 1. Overall Weighted Average Effect Size for Cross-Sectional Studies and Heterogeneity Statistics

\begin{tabular}{|l|c|c|c|c|}
\hline $\begin{array}{l}\text { Population Estimates } \\
\text { (Strength of RAN-to- } \\
\text { Reading Association) }\end{array}$ & $K$ & $r^{+}$ & Cl: Lower 95 & Cl: Upper 95 \\
\hline $\begin{array}{l}\text { Random Effects } \\
\text { Model }\end{array}$ & 1254 & $0.314^{* *}$ & 0.31 & 0.32 \\
\hline Fixed Effect Model & 1254 & $0.321^{* *}$ & 0.32 & 0.33 \\
\hline $\begin{array}{l}\text { Heterogeneity } \\
\text { Analysis }\end{array}$ & $Q_{\text {Total }}=2879.57$ (df $=1253$ ), $p<0.001,1^{2}=56.49$ \\
\hline$* * p<0.01$ & \multicolumn{3}{|l}{} \\
\hline
\end{tabular}

Table 2. Overall Weighted Average Effect Size for Longitudinal Studies and Heterogeneity Statistics

\begin{tabular}{|l|c|c|c|c|}
\hline $\begin{array}{l}\text { Population Estimates } \\
\text { (Strength of RAN-to- } \\
\text { Reading Association) }\end{array}$ & $K$ & $r^{+}$ & Cl: Lower 95 & Cl: Upper 95 \\
\hline $\begin{array}{l}\text { Random Effects } \\
\text { Model }\end{array}$ & 297 & $0.343^{* *}$ & 0.33 & 0.36 \\
\hline Fixed Effect Model & 297 & $0.350^{* *}$ & 0.34 & 0.45 \\
\hline $\begin{array}{l}\text { Heterogeneity } \\
\text { Analysis }\end{array}$ & $Q_{\text {Total }}=418.43(d f=296), p=0.003,1^{2}=29.26$ \\
\hline$* * p<0.01$ & \multicolumn{3}{|l}{} \\
\hline
\end{tabular}

According to the random effects analytical model, the average effect size (strength of association expressed as correlation coefficients) in cross-sectional investigations was $r^{+}=0.314$, statistically significant $(p<0.01)$ and highly heterogeneous $(p<0.001)$. The average effect size based on longitudinal data was $r^{+}=0.343$, also statistically significant $(p<0.01)$ and moderately but significantly heterogeneous $(p=0.003)$. Both effects could be classified as indicating a low-to-moderate degree of association between naming speed and various measures of reading performance, while significant heterogeneity (assessed within the fixed effect model) of both distributions of effect sizes warranted 
further exploration of findings by means of moderator variable analyses to detect systematic variations due to specific study characteristics (categorized and coded as it was described earlier in the method section). Major findings of these analyses are presented below in Table 3 and Table 4 - for cross-sectional and longitudinal data, respectively. While some levels of age and reading abilities described for cross-sectional studies were not found in the reviewed empirical literature for longitudinal studies, one additional variable - the time delay between administering measures of RAN and reading performance - was added and analysed there.

Table 3. Significant Moderator Variables (Mixed Model) for Cross-Sectional Studies

\begin{tabular}{|c|c|c|c|c|c|}
\hline Variables/Levels & $k$ & $r^{+}$ & $\begin{array}{c}\text { Lower } \\
95^{\text {th }}\end{array}$ & $\begin{array}{c}\text { Upper } \\
95^{\text {th }}\end{array}$ & $\begin{array}{c}Q_{B}(d f, p) \\
\text { Conclusion }^{a}\end{array}$ \\
\hline \multicolumn{6}{|l|}{ RAN Type: } \\
\hline Symbolic RAN & 682 & 0.346 & 0.33 & 0.36 & \\
\hline Non-Symbolic RAN & 373 & 0.259 & 0.25 & 0.27 & \\
\hline Modified RAN & 129 & 0.274 & 0.24 & 0.31 & \\
\hline Mixed-Stimuli RAN & 70 & 0.330 & 0.29 & 0.37 & \\
\hline Q-Between & & & & & $\begin{array}{c}105.57 \\
(3,<0.001), S D\end{array}$ \\
\hline \multicolumn{6}{|c|}{ Measures of Reading Performance: } \\
\hline Reading Composites & 26 & 0.347 & 0.28 & 0.41 & \\
\hline Decoding Skills & 242 & 0.333 & 0.32 & 0.35 & \\
\hline Orthography & 56 & 0.260 & 0.22 & 0.30 & \\
\hline $\begin{array}{l}\text { Reading } \\
\text { Comprehension }\end{array}$ & 198 & 0.300 & 0.28 & 0.32 & \\
\hline Reading Rate & 155 & 0.369 & 0.35 & 0.40 & \\
\hline Spelling & 87 & 0.283 & 0.25 & 0.31 & \\
\hline $\begin{array}{l}\text { Vocabulary } \\
\text { Knowledge }\end{array}$ & 122 & 0.172 & 0.14 & 0.20 & \\
\hline Word Reading & 368 & 0.350 & 0.34 & 0.36 & \\
\hline Q-Between & & & & & $\begin{array}{c}179.66 \\
(7,<0.01), S D\end{array}$ \\
\hline
\end{tabular}




\begin{tabular}{|c|c|c|c|c|c|}
\hline Variables/Levels & $k$ & $r^{+}$ & $\begin{array}{l}\text { Lower } \\
95^{\text {th }}\end{array}$ & $\begin{array}{l}\text { Upper } \\
95^{\text {th }}\end{array}$ & $\begin{array}{c}Q_{B}(d f, p) \\
\text { Conclusion }\end{array}$ \\
\hline \multicolumn{6}{|l|}{ Participants' Age Group: } \\
\hline Kindergarten & 109 & 0.287 & 0.26 & 0.31 & \\
\hline Elementary School & 645 & 0.324 & 0.31 & 0.34 & \\
\hline Middle School & 104 & 0.268 & 0.24 & 0.30 & \\
\hline $\begin{array}{l}\text { High School } \\
\text { (Teenagers) }\end{array}$ & 7 & 0.424 & 0.36 & 0.38 & \\
\hline Adults & 201 & 0.277 & 0.25 & 0.30 & \\
\hline $\begin{array}{l}\text { Mixture of Several Age } \\
\text { Groups }\end{array}$ & 188 & 0.337 & 0.32 & 0.36 & \\
\hline Q-Between & & & & & $\begin{array}{c}42.93 \\
(5,0.003), S D\end{array}$ \\
\hline \multicolumn{6}{|l|}{ Reading Ability: } \\
\hline $\begin{array}{l}\text { Developmental } \\
\text { Dyslexia }\end{array}$ & 327 & 0.325 & 0.31 & 0.34 & \\
\hline Learning Disabilities & 48 & 0.216 & 0.15 & 0.28 & \\
\hline Mixed-Ability Readers & 188 & 0.342 & 0.32 & 0.36 & \\
\hline $\begin{array}{l}\text { Average Readers } \\
\text { (General Population) }\end{array}$ & 691 & 0.306 & 0.29 & 0.32 & \\
\hline Q-Between & & & & & $\begin{array}{c}20.25 \\
(3,0.015), S D\end{array}$ \\
\hline
\end{tabular}

Note: ${ }^{a}$ Between-level statistically significant differences (SD) and statistically non-significant differences (NSD), numbers in parentheses reflect $d f$ and $p$-values. 
ОБЩАЯ ПСИХОЛОГИЯ

Table 4. Significant Moderator Variables (Mixed Model) for Longitudinal Studies

\begin{tabular}{|c|c|c|c|c|c|}
\hline Variables/Levels & $k$ & $r^{+}$ & $\begin{array}{c}\text { Lower } \\
95^{\text {th }}\end{array}$ & $\begin{array}{c}\text { Upper } \\
95^{\text {th }}\end{array}$ & $\begin{array}{c}Q_{B}(d f, p) \\
\text { Conclusion }^{a}\end{array}$ \\
\hline \multicolumn{6}{|l|}{ RAN Type: } \\
\hline Symbolic RAN & 170 & 0.368 & 0.35 & 0.39 & \\
\hline Non-Symbolic RAN & 119 & 0.306 & 0.28 & 0.32 & \\
\hline Modified RAN & 3 & 0.487 & 0.44 & 0.53 & \\
\hline Mixed-Stimuli RAN & 5 & 0.409 & 0.32 & 0.49 & \\
\hline Q-Between & & & & & $\begin{array}{c}59.86 \\
(3,<0.001), S D\end{array}$ \\
\hline \multicolumn{6}{|c|}{ Measures of Reading Performance: } \\
\hline Reading Composites & 14 & 0.367 & 0.25 & 0.47 & \\
\hline Decoding Skills & 50 & 0.333 & 0.29 & 0.37 & \\
\hline Orthography & 6 & 0.281 & 0.18 & 0.38 & \\
\hline $\begin{array}{l}\text { Reading } \\
\text { Comprehension }\end{array}$ & 61 & 0.321 & 0.29 & 0.35 & \\
\hline Reading Rate & 48 & 0.358 & 0.32 & 0.39 & \\
\hline Spelling & 29 & 0.334 & 0.30 & 0.37 & \\
\hline $\begin{array}{l}\text { Vocabulary } \\
\text { Knowledge }\end{array}$ & 10 & 0.145 & 0.05 & 0.23 & \\
\hline Word Reading & 79 & 0.380 & 0.36 & 0.40 & \\
\hline Q-Between & & & & & $\begin{array}{c}35.51 \\
(7,0.008), S D\end{array}$ \\
\hline \multicolumn{6}{|c|}{ Participants' Age Group (at the time of RAN administration): } \\
\hline Kindergarten & 116 & 0.339 & 0.32 & 0.36 & \\
\hline Elementary School & 181 & 0.346 & 0.33 & 0.37 & \\
\hline Q-Between & & & & & $\begin{array}{c}0.25 \\
(1,0.62), \text { NSD }\end{array}$ \\
\hline
\end{tabular}




\begin{tabular}{|c|c|c|c|c|c|}
\hline Variables/Levels & $k$ & $r^{+}$ & $\begin{array}{l}\text { Lower } \\
95^{\text {th }}\end{array}$ & $\begin{array}{l}\text { Upper } \\
95^{\text {th }}\end{array}$ & $\begin{array}{c}Q_{B}(d f, p) \\
\text { Conclusion }\end{array}$ \\
\hline \multicolumn{6}{|l|}{ Reading Ability: } \\
\hline $\begin{array}{l}\text { Developmental } \\
\text { Dyslexia }\end{array}$ & 60 & 0.318 & 0.28 & 0.36 & \\
\hline Mixed-Ability Readers & 24 & 0.352 & 0.31 & 0.39 & \\
\hline $\begin{array}{l}\text { Average Readers } \\
\text { (General Population) }\end{array}$ & 213 & 0.343 & 0.33 & 0.36 & \\
\hline Q-Between & & & & & $\begin{array}{c}1.64 \\
(2,0.44), N S D\end{array}$ \\
\hline \multicolumn{6}{|c|}{ Time Delay (between administering measures of RAN and Reading): } \\
\hline Within a Year & 111 & 0.360 & 0.34 & 0.38 & \\
\hline Over a Year & 186 & 0.329 & 0.31 & 0.34 & \\
\hline Q-Between & & & & & $\begin{array}{c}4.603 \\
(1,0.045), S D\end{array}$ \\
\hline
\end{tabular}

Note: ${ }^{a}$ Between-level statistically significant differences (SD) and statistically non-significant differences (NSD), numbers in parentheses reflect $d f$ and $p$-values.

For each of significant moderator variables, post hoc pair-wise comparisons among their levels (using Bonferroni correction) were implemented to identify the major sources of difference among effect sizes. It is worth mentioning here that we considered the number of cases fewer than 10 to be insufficient for any meaningful interpretation of the corresponding levels of moderator variables under review. In brief summary, here are the major findings of these analyses.

Effects sizes for symbolic RAN were significantly higher than for non-symbolic RAN in both cross-sectional and longitudinal categories $\left(r^{+}=0.35 \mathrm{vs}\right.$. $r^{+}=0.26$ and $r^{+}=0.37$ vs. $r^{+}=0.31$, respectively). For all measures of RAN performance within the cross-sectional collection, its association with reading rate $\left(r^{+}=0.37\right)$ was the strongest, significantly higher than with reading comprehension $\left(r^{+}=0.30\right)$, spelling $\left(r^{+}=0.28\right)$, orthographic skills $\left(r^{+}=0.27\right)$, and vocabulary knowledge $\left(r^{+}=0.17\right)$. The latter was the weakest correlate of RAN performance (significantly lower than any other measure). RAN correlations with 
word reading, decoding skills, and reading composite measures did not differ significantly either from one another or from reading rate (Table 3). Setting aside seven cases of high-school students and the mixed-age category, the only marginally significant difference by learners' age (academic level) was observed between elementary and secondary (middle-school) students in favour of the former $\left(r^{+}=0.32\right.$ vs. $\left.r^{+}=0.27\right)$. In the category of population type / reading ability, samples of students with learning disabilities on average produced significantly weaker correlations between RAN and reading $\left(r^{+}=0.22\right)$ than other sub-categories (including samples of students diagnosed with developmental dyslexia $-r^{+}=0.32$ ) that were virtually indistinguishable from one another. No statistically significant differences among RAN-to-reading correlations among coded levels of the language category were detected.

Longitudinal dataset was much smaller in size, subsequently featuring lesser number of levels per category and number of cases per level (and likely lacking sufficient statistical power), produced fewer number of significant findings. Similarly to cross-sectional collection, the weakest correlation between RAN performance and measures of vocabulary knowledge $\left(r^{+}=0.14\right)$ was significantly different from all other RAN-to-reading correlations, among which the strongest ones - for word reading $\left(r^{+}=0.38\right)$, reading composite $\left(r^{+}=0.37\right)$, and reading rate $\left(r^{+}=0.36\right)$ differed neither among themselves nor from decoding skills, spelling, and reading comprehension (Table 4). Marginally significant difference between correlations of measures of RAN and reading administered within a year $\left(r^{+}=0.36\right)$ and after a longer time period $\left(r^{+}=0.33\right)$, may be indicative of the tendency that with time predictive capacity of RAN task diminishes as reading skills themselves progress and other (contextual and educational factors) gain in their influence on literacy development.

Of utmost importance for the current project were relationships between various types of RAN task and specific reading skills that would be not only statistically significant, but also sufficiently coherent, as judged by homogeneity of within-group distributions of effect sizes at each level of this moderator variable (e. g., Symbolic RAN x Reading Rate, Non-Symbolic RAN x Reading Comprehension and so on). Both cross-sectional and longitudinal datasets were explored further to assess and describe these associations.

Moderator variable analyses of cross-sectional data produced very few highly significant and homogeneous (or approaching homogeneity) sets of effects across the RAN-by-reading category. Among the most coherent subsets were associations between: (1) symbolic RAN and measures of reading speed $\left(r^{+}=0.42, k=72\right.$; $\left.Q_{\text {Within }}=71.47, p=0.46\right)$; (2) symbolic RAN and reading composites $\left(r^{+}=0.50, k=9\right.$; $\left.Q_{\text {Within }}=5.37, p=0.72\right) ;(3)$ either type of RAN task and decoding skills $\left(r^{+}=0.37\right.$, $k=151 ; Q_{\text {Within }}=181.0, p=0.04$ and $r^{+}=0.28, k=71 ; Q_{\text {Within }}=96.58, p=0.02-$ for 


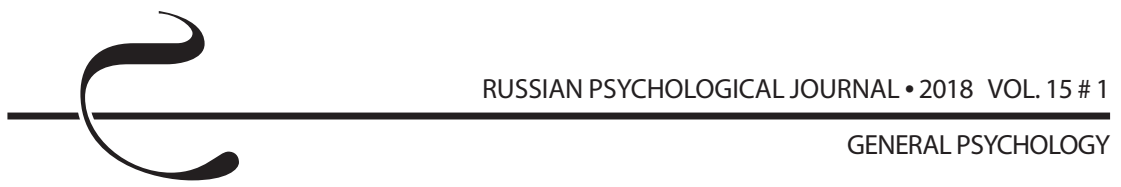

symbolic and non-symbolic RAN tasks, respectively); and (4) non-symbolic RAN and measures of reading comprehension $\left(r^{+}=0.30, k=37 ; Q_{\text {Within }}=38.33, p=0.36\right)$. It may also be important to recognise that all effects for symbolic RAN were higher than the corresponding effects for non-symbolic RAN with the highest effects for reading speed $\left(r^{+}=0.42\right)$, individual word reading $\left(r^{+}=0.40\right)$, and decoding skills $\left(r^{+}=0.37\right)$ - whereas the corresponding effects for non-symbolic RAN were: $r^{+}=0.30, r^{+}=0.26$, and $r^{+}=0.28$, respectively. Among other moderator variables the highest consistency (though not reaching the level of statistical significance) of RAN-to-reading degree of association was shown for kindergarteners $\left(r^{+}=0.28\right.$, $k=109 ; Q_{\text {Within }}=136.82, p=0.03$.

Within the longitudinal data collection, effects tended to be more coherent (possibly due to the reduced variability typically associated with a smaller number of cases per level per category, but still reflective of some true consistency of RAN-to-reading associations). Significantly homogeneous effect sizes were observed for: (1) the overall non-symbolic RAN $\left(r^{+}=0.31, k=119\right.$; $\left.Q_{\text {Within }}=31.95, p=0.64\right)$; (2) for measures of reading speed $\left(r^{+}=0.36, k=48\right.$; $\left.Q_{\text {Within }}=44.32, p=0.58\right)$, reading comprehension $\left(r^{+}=0.32, k=61 ; Q_{\text {Within }}=52.32\right.$, $p=0.75)$, and spelling $\left(r^{+}=0.33, k=29 ; Q_{\text {Within }}=27.83, p=0.47\right) ;(3)$ in participants with reading impairments classified as different degrees of developmental dyslexia $\left(r^{+}=0.32, k=60 ; Q_{\text {Within }}=39.22, p=0.98\right) ;$ and (4) when the time lag between administering RAN and reading measures exceeded a year $\left(r^{+}=0.33\right.$, $\left.k=186 ; Q_{\text {within }}=181.59, p=0.56\right)$. In combinations with different aspects of reading performance, effects for symbolic RAN, once again, were higher than for non-symbolic RAN, with the same top three: word reading $\left(r^{+}=0.43\right.$, $k=47)$, reading speed $\left(r^{+}=0.43, k=32\right)$, and decoding skills $\left(r^{+}=0.40, k=29\right)$. However, for longitudinal data that difference was less dramatic $\left(r^{+}=0.32, k=40\right.$; $r^{+}=0.29, k=16$; and $r^{+}=0.27, k=19-$ for the aforementioned categories of reading measures respectively). All of them were significantly homogeneous (i. e., consistent across studies) with the corresponding $Q_{\text {within }}$ values not exceeding 50.53 (symbolic RAN correlation with measures of word reading, $p=0.30$ ). The strongest non-symbolic RAN association was observed with the various measures of reading comprehension $\left(r^{+}=0.33, k=21\right)$, which was also significantly homogeneous $\left(Q_{\text {Within }}=14.55, p=0.80\right)$.

Finally, it makes sense to add that correlation coefficients between RAN task performance and composite measures of reading (i. e., accounting for more than one specific aspect of reading skills within the same assessment index or in other words representing the reading competency as a whole phenomenon) were among highest in magnitude, though not necessarily achieving the level of homogeneity. It was true for both cross-sectional and longitudinal categories of studies: $r^{+}=0.38, k=26$ and $r^{+}=0.37, k=14$, respectively. 


\section{Discussion}

The patterns of effect sizes (i. e., coefficients of correlation between various RAN tasks and measures of reading skills) in the cross-sectional and longitudinal studies were similar, with slightly higher average point estimate for the latter. Whereas a direct statistical relationship between the two is not possible (as these effects were derived from different samples), this difference does not appear to be substantial enough to speculate that RAN task performance is better used for predicting progress in reading outcomes, especially since, within the longitudinal collection itself, there was no significant difference between the RAN-to-reading correlations for the same year assessments and assessments separated by longer time periods.

Both overall $r^{+}$were heterogeneous, which prevents drawing any definitive conclusions about the degree of strength of the RAN-to-reading association in general population, though it is obvious that this association is overwhelmingly positive and quite compatible across various levels of the major moderator variables. In our review, average coefficients of correlations for cross-sectional data varied from 0.14 (between measures of symbolic RAN and vocabulary knowledge) to 0.50 (between measures of symbolic RAN and a few cases of reported reading composites). Two similar correlations defined the range of average effect sizes in the longitudinal collection: 0.09 (between measures of symbolic RAN and vocabulary knowledge) and 0.45 (between measures of non-symbolic RAN and just four cases of reading composites). These are not particularly wide ranges and, if set vocabulary knowledge aside from other reading skills (as it is more dependent on exposure to proper educational interventions and communicatively rich environments and is much less associated with speed-sensitive cognitive processing), the absolute majority of RAN-to-reading correlations in both collection cluster closely around their respective means.

Moderator variable analyses produced some interesting homogeneous (thus, more reliably interpretable) results. Cross-sectionally, symbolic RAN subtasks tended to be more strongly correlated with reading rate, reading comprehension, and decoding skills, whereas non-symbolic RAN subtasks showed consistent, though somewhat lower, correlations with reading comprehension and decoding skills. Reading rate, decoding, and to some extent, comprehension either require expertise with printed text (which relates this pattern of results to findings of a meta-analysis [96]) or depend on processing speed, or both, and as such, could be linked to practice-based cognitive mechanisms of reading. Also, decoding and comprehension largely depend on applying rules and building associations. In this respect, their consistent correlations with non-symbolic RAN subtasks is suggestive of the involvement of attention-based mechanisms earlier hypothesized and tested in [110] and [109]. Actually, the latter research demonstrated high 
sensitivity of both types of RAN to manipulations with the levels of demand for attentional control, leading the author to wonder what " $\mathrm{A}$ " in RAN should stand for.

The patterns of longitudinal results basically mirrored that of cross-sectional data. Two measures in particular - reading rate and reading comprehension - were consistently (i. e., heterogeneity scores within the respective sub-collections of data were relatively low) correlated with overall RAN performance. Once again, associations were stronger between symbolic RAN and reading rate and between non-symbolic RAN and reading comprehension, but not vice versa. Interestingly enough, longitudinal effects across practically all individual moderators tended to be more homogeneous in comparison with cross-sectional data, possibly indicating that the RAN task, as a correlate of reading abilities, is more consistent when it is used for prognosis of future reading performance rather then as a diagnostic tool for current deficiencies. Also, note that RAN-to-reading correlations in a subgroup of participants diagnosed with reading impairments, though fairly consistent, were not among the strongest in either collection.

Observed patterns of correlation neither support directly nor seriously contradict the double deficit hypothesis [23]. Strong association of measures of decoding skill (that have phonological processing in its core) with RAN performance puts in question hypothesized independence of naming speed and phonological awareness. Also, speed-sensitive and attention-demanding reading competencies did not differ substantially in their associations with RAN task performance. It the light of these findings (including strong RAN associations with reading composite measures), it appears reasonable to suggest that the RAN task performance is based on, so to speak, "pre-reading" skills that combine automatic and controlled cognitive processes necessarily involved in successful reading activities of all types.

In concluding remarks, despite some reservations expressed in previous meta-analyses, the RAN task connection to reading should not be considered inferior to that of other correlates/predictors. RAN still deserves special attention as an assessment tool for research on literacy acquisition across age groups, especially when learners (for whatever reasons) may be less responsive to regular instruction in reading.

Better understanding of the cognitive mechanisms underlying RAN task performance in its association with reading has a high potential for informing researchers and educational practitioners of possible reasons for reading problems and, thus, for guiding them to design more effective literacy interventions. Reading for comprehension, vocabulary enrichment, fluency in complex pattern recognition, even second language learning may benefit from the understanding of the role played by both automaticity and attention in naming speed and reading. Some special tools and practices directed toward achieving a better management of 
attentional resources may be developed and used in early literacy education to complement reading training oriented toward achieving higher fluency to better the overall reading competency of learners.

\section{References}

1. Critchley M. The Dyslexic Child (2nd ed.). Springfield, III, Charles C. Thomas, 1970. 137 p. DOI: 10.1002/1520-6807(197304)10:2<264::AIDPITS2310100227>3.0.CO;2-P

2. Snowling M. J. Dyslexia. Oxford, UK, Blackwell Publishers Ltd., 2000. 253 p.

3. Bishop D.V.M. Uncommon understanding:Development and disorders of language comprehension in children. Cambridge, UK, Psychology Press Ltd., 1997. 288 p.

4. Vellutino F. R. \& Fletcher J. M. Developmental Dyslexia. In: M. J. Snowling \& C. Hulme (eds.) The science of reading:A handbook. Blackwell handbooks of developmental psychology. Malden, MA, Blackwell Publishing, 2005, pp. 362-378.

5. Savage R. Motor skills, automaticity and developmental dyslexia: A review of the research literature. Reading and Writing, 2004, V. 17, Issue 3, pp. 301-324. DOI: 10.1023/B:READ.0000017688.67137.80

6. Bradley L., \& Bryant P. E. Categorizing sounds and learning to read - a causal connection. Nature, 1983, V. 301, pp. 419-421. DOI: 10.1038/301419a0

7. Fawcett A. (Ed.) Dyslexia, theory and good practice. London, Whurr, 2001.321 p.

8. Rayner K., Foorman B. R., Perfetti C. A., Pesetsky D., Seidenberg M. S. How Psychological Science Informs the Teaching of Reading. Psychological Science in the Public Interest, 2001, V. 2, Issue 2, pp. 31-74. DOI: 10.1111/1529-1006.00004

9. Stanovich K. E. Progress in Understanding Reading: Scientific Foundations and New Frontiers. New York, NY, Guilford Press, 2000. 548 p.

10. Gallagher A., \& Frederickson N. The phonological assessment battery (PhAB): An initial assessment of its theoretical and practical utility. Educational and Child Psychology, 1995, V. 12 (1), pp. 53-67.

11. Stanovich K. E., Cunningham A. E., \& Feeman D. J. Intelligence, Cognitive Skills, and Early Reading Progress. Reading Research Quarterly, 1984, V. 19, no. 3, pp. 278-303. DOI: 10.2307/747822

12. Bone R. B., Cirino P., Morris R. D. \& Morris M. K. Reading and Phonological Awareness in Reading-Disabled Adults. Developmental Neuropsychology, 2002, V. 21, Issue 3, pp. 306-320. DOI: 10.1207/S15326942DN2103_6

13. Fleming K. M. The effect of instruction, rapid automatized naming, intellectual functioning, initial phonological awareness skill, and age on phonological awareness growth trajectories. Diss. Dr. Sci. Eugene, OR, 1999. Available at: https://elibrary.ru/item.asp?id=5353309 (Accessed 10 March 2018).

14. Wilson J., \& Frederickson N. Phonological awareness training: An evaluation. Educational and Child Psychology, 1995, V. 12 (1), pp. 68-79. 
15. Abrami P. C., Borokhovski E., \& Lysenko L. V. The effects of ABRACADABRA on reading outcomes: A meta-analysis of applied field research data. Journal of Interactive Learning Research, 2015, V. 26 (4), pp. 337-367.

16. Lu T. The relationship of phonological processing (phonological awareness, verbal short-term memory, and rapid naming) and visual short-term memory to reading disabilities in Chinese children. Diss. Dr. Sci. lowa City, IA, 2004. Available at: PQDT Open (Accessed 10 March 2018).

17. Xiangzhi M., Shuying S., \& Xiaolin Z. Phonological awareness, naming speed and Chinese reading. Psychological Science (China), 2004, V. 27 (6), pp. 1326-1329.

18. de Jong P. F., van der Leij A. Developmental changes in the manifestation of a phonological deficit in dyslexic children learning to read a regular orthography. Journal of Educational Psychology, 2003, V. 95 (1), pp. 22-40. DOI: 10.1037/0022-0663.95.1.22

19. Landerl K. Dyslexia in German-speaking children. In: N. Goulandris (ed.) Dyslexia in different languages: Cross-linguistic comparisons. London, Whurr Publishers, Ltd., 2003, pp. 15-32.

20. Lafrance A., \& Gottardo A. A longitudinal study of phonological processing skills and reading in bilingual children. Applied Psycholinguistics, 2005, V. 26, Issue 4, pp. 559-578. DOI: 10.1017/S0142716405050307

21. Veii K. \& Everatt J. Predictors of reading among Herero-English bilingual Namibian school children. Bilingualism: Language and Cognition, 2005, V. 8, Issue 3, pp. 239-254. DOI: 10.1017/S1366728905002282

22. van der Leij A., Morfidi E. Core Deficits and Variable Differences in Dutch Poor Readers Learning English. Journal of Learning Disabilities, 2006, V. 39, Issue 1, pp. 74-90. DOI: 10.1177/00222194060390010701

23. Wolf M., Bowers P. G. The double-deficit hypothesis for the developmental dyslexias. Journal of Educational Psychology, 1999, V. 91 (3), pp. 415-438. DOI: $10.1037 / 0022-0663.91 .3 .415$

24. Lovett M. W., Steinbach K. A., and Frijters J. C. Remediating the Core Deficits of Developmental Reading Disability: A double-deficit perspective. Journal of Learning Disabilities, 2000, V. 33, Issue 4, pp. 334-358. DOI: 10.1177/002221940003300406

25. Manis F. R., Doi L. M., Bhadha B. Naming Speed, Phonological Awareness, and Orthographic Knowledge in Second Graders. Journal of Learning Disabilities, 2000, V. 33, Issue 4, pp. 325-333. DOI: 10.1177/002221940003300405

26. Manis F. R., Lindsey K. A., Bailey C. E. Development of Reading in Grades $\mathrm{K}-2$ in Spanish-Speaking English-Language Learners. Learning Disabilities Research \& Practice, 2004, V. 19, Issue 4, pp. 214-224. DOI: 10.1111/j.15405826.2004.00107.x 
27. Berninger V. W., Abbott R. D., Thomson J. B., \& Raskind W. H. Language Phenotype for Reading and Writing Disability: A Family Approach. Scientific Studies of Reading, 2001, V. 15, Issue 1, pp. 59-106. DOI: 10.1207/ S1532799XSSR0501_3

28. Biddle K. R. Timing deficits in impaired readers: An investigation of visual naming speed and verbal fluency. Diss. Dr. Sci. MA, 1997.

29. Krug C. H. The diagnostic implications of the double-deficit hypothesis: An investigation of fifth-grade readers classified by phonological awareness and visual naming speed. Diss. Dr. Sci. Medford, MA, 1996. Available at: PQDT Open (Accessed 10 March 2018).

30. Meyer M. S., Wood F. B., Hart L. A., Felton R. H. Selective Predictive Value of Rapid Automatized Naming in Poor Readers. Journal of Learning Disabilities, 1998, V. 31, Issue 2, pp. 106-117. DOI: 10.1177/002221949803100201

31. Neuhaus G. F., Swank P. R. Understanding the Relations Between RAN Letter Subtest Components and Word Reading in First-Grade Students. Journal of Learning Disabilities, 2002, V. 35, Issue 2, pp. 158-174. DOI: $10.1177 / 002221940203500206$

32. Petterson S. M. The double-deficit hypothesis: An investigation of isolated word fluency by students classified as single visual naming speed deficit or phonological deficit. Diss. Dr. Sci. Detroit, MI, 2001. Available at: PQDT Open (Accessed 10 March 2018).

33. Wolf M., Bowers P. G., Biddle K. Naming-Speed Processes, Timing, and Reading: A Conceptual Review. Journal of Learning Disabilities, 2000, V. 33, Issue 4, pp. 387-407. DOI: 10.1177/002221940003300409

34. Harn E. A. Examining and predicting response to instruction based on kindergarten children's early literacy profiles. Diss. Dr. Sci. Eugene, OR, 2000. Available at: PQDT Open (Accessed 10 March 2018).

35. Nopola-Hemmi J., Myllyluoma B., Voutilainen A., Leinonen S., Kere J., Ahonen T. Familial dyslexia: neurocognitive and genetic correlation in a large Finnish family. Developmental Medicine \& Child Neurology, 2002, V. 44, Issue 9, pp. 580-586. DOI: 10.1111/j.1469-8749.2002.tb00842.x

36. Fletcher J. M., Morris R., Lyon G. R., Stuebing K. K., Shaywitz S. E., Shankweiler D. P., Katz L., \& Shaywitz B. A. Subtypes of dyslexia: An old problem revisited. In: B. A. Blachman (ed.) Foundations of reading acquisition and dyslexia:Implications for early intervention. Lawrence Erlbaum Associates, Publishers, 1997, pp. 95-114.

37. Tiu R. D., Wadsworth S. J., Olson R. K., \& DeFries J. C. Causal Models of Reading Disability: A Twin Study. Twin Research, 2004, V. 7, Issue 3, pp. 275-283. DOI: 10.1375/twin.7.3.275

38. Schatschneider C., Carlson C. D., Francis D. J., Foorman B. R., Fletcher J. M. Relationship of Rapid Automatized Naming and Phonological Awareness in 
Early Reading Development: Implications for the Double-Deficit Hypothesis. Journal of Learning Disabilities, 2002, V. 35, Issue 3, pp. 245-256. DOI: 10.1177/002221940203500306

39. Ackerman P.T., Holloway C. A., Youngdahl P. L., Dykman R. A. The Double-Deficit Theory of Reading Disability Does Not Fit All. Learning Disabilities Research \& Practice, 2001, V. 16, Issue 3, pp. 152-160. DOI: 10.1111/0938-8982.00016

40. Watkins M. W., Kush J. C., Glutting J. J. Discriminant and predictive validity of the WISC-III ACID profile among children with learning disabilities. Psychology in the Schools, 1997, V. 34, Issue 4, pp. 309-319. DOI: 10.1002/ (SICI)1520-6807(199710)34:4<309::AID-PITS2>3.0.CO;2-G

41. Geschwind N. Disconnection syndrome in animals and man (Part I). Brain, 1965, V. 88, pp. 237-294.

42. Geschwind N. Disconnection syndrome in animals and man (Part II). Brain, 1965, V. 88, pp. 585-644.

43. Denckla M. B. Color-Naming Defects in Dyslexic Boys. Cortex, 1972, V. 8, Issue 2, pp. 164-176. DOI: 10.1016/S0010-9452(72)80016-9

44. Denckla M. B., Rudel R. G. Rapid 'automatized' naming (R.A.N.): Dyslexia differentiated from other learning disabilities. Neuropsychologia, 1976, V. 14, Issue 4, pp. 471-479. DOI: 10.1016/0028-3932(76)90075-0

45. Fawcett A., \& Nicolson R. Dyslexia in children: multidisciplinary perspectives. Englewood Cliffs, NJ, Prentice Hall, 1994a. 272 p.

46. Mitchell J.-J.ComprehensiveTest of Phonological Processing.AssessmentforEffective Intervention, 2001,V.26, Issue 3, pp. 57-63.DOI: 10.1177/073724770102600305

47. Nicolson R. I. \& Fawcett A. J. Dyslexia screening test. London, The Psychological Corporation, 1996. $63 \mathrm{p}$.

48. Denckla M. B., Rudel R. G. Naming of object-drawings by dyslexics and other learning disabled children. Brain and Language, 1976, V. 3, Issue 1, pp. 1-15. DOI: 10.1016/0093-934X(76)90001-8

49. Etmanskie J. M. Reading, spelling, and phonological processing in children with phonological or surface reading problems. Diss. Dr. Sci. Kingston, ON, 1999. Available at: PQDT Open (Accessed 10 March 2018).

50. Fawcett A. J., Nicolson R. I. Naming Speed in Children with Dyslexia. Journal of Learning Disabilities, 1994, V. 27, Issue 10, pp. 641-646. DOI: 10.1177/002221949402701004

51. Felton R. H., Naylor C. E., Wood F. B. Neuropsychological profile of adult dyslexics. Brain and Language, 1990, V. 39, Issue 4, pp. 485-497. DOI: 10.1016/0093-934X(90)90157-C

52. Aarnoutse C., van Leeuwe J. \& Verhoeven L. Early Literacy From a Longitudinal Perspective. Educational Research and Evaluation, 2005, V. 11, Issue 3, pp. 253-275. DOI: 10.1080/08993400500101054 
53. Cronin V., \& Carver P. Phonological sensitivity, rapid naming, and beginning reading. Applied Psycholinguistics, 1998, V. 19, Issue 3, pp. 447-461. DOI: 10.1017/S0142716400010262

54. Scarborough H. S. Predicting the future achievement of second graders with reading disabilities: Contributions of phonemic awareness, verbal memory, rapid naming, and IQ. Annals of Dyslexia, 1998, V. 48, Issue 1, pp. 115-136. DOI: 10.1007/s11881-998-0006-5

55. Sprugevica I. The impact of enabling skills on early reading acquisition. Diss. Dr. Sci. Universitetet i Bergen (Norway), 2003. Available at: https://dspace.lu.lv/ dspace/bitstream/handle/7/1179/Sprugevica_I_The_impact_of_enabling_ skills_2002.pdf?sequence=1\&isAllowed=y (Accessed 10 March 2018).

56. Sprugevica I., \& Hoien T. Relations between enabling skills and reading comprehension: A follow-up study of Latvian students from first to second grade. Scandinavian Journal of Psychology, 2004, V. 45, Issue 2, pp. 115-122. DOI: 10.1111/j.1467-9450.2004.00386.x

57. Uhry J. K. Kindergarten phonological awareness and rapid serial naming as predictors of grade 2 reading and spelling. In: E. Witruk, A. D. Friederici \& T. Lachmann (eds.) Basic functions of language, reading and reading disability. New York, NY, Kluwer Academic Publishers, 2002, pp. 299-313.

58. Vellutino F. R., Scallon D., \& Sipay E. R. Toward distinguishing between cognitive and experiential deficits as primary sources of difficulty in learning to read: The importance of early intervention in diagnosing specific reading disability. In: B. A. Blachman (ed.) Foundations of reading acquisition and dyslexia:Implications for early intervention. Hillsdale, NJ, Lawrence Erlbaum, 1997, pp. 145-162.

59. Wimmer H., Mayringer H., Landerl K. The double-deficit hypothesis and difficulties in learning to read a regular orthography. Journal of Educational Psychology, 2000, V. 92 (4), pp. 668-680. DOI: 10.1037/0022-0663.92.4.668

60. Ackerman P. T., Dykman R. A. Phonological Processes, Confrontational Naming, and Immediate Memory in Dyslexia. Journal of Learning Disabilities, 1993, V. 26, Issue 9, pp. 597-609. DOI: 10.1177/002221949302600910

61. Badian N. A. Phonemic awareness, naming, visual symbol processing, and reading. Reading and Writing, 1993, V. 5, Issue 1, pp. 87-100. DOI: 10.1007/ BF01026920

62. Badian N. A. Preschool prediction: Orthographic and phonological skills, and reading. Annals of Dyslexia, 1994, V. 44, Issue 1, pp. 1-25. DOI: 10.1007/ BF02648153

63. Cornwall A. The Relationship of Phonological Awareness, Rapid Naming, and Verbal Memory to Severe Reading and Spelling Disability. Journal of Learning Disabilities, 1992, V. 25, Issue 8, pp. 532-538. DOI: $10.1177 / 002221949202500808$ 
64. Bowers P. G., Kennedy A. Effects of Naming Speed Differences on Fluency of Reading after Practice. Annals of the New York Academy of Sciences, 1993, V. 682 (1), pp. 318-320. DOI: 10.1111/j.1749-6632.1993.tb22980.x

65. de Jong P. F., Vrielink L. O. Rapid automatic naming: Easy to measure, hard to improve (quickly). Annals of Dyslexia, 2004, V. 54, Issue 1, pp. 65-88. DOI: 10.1007/s11881-004-0004-1

66. van den Bos K. P. IQ, phonological awareness, and continuous-naming speed related to Dutch poor decoding children's performance on two word identification tests. Dyslexia, 1998, V. 4, Issue 2, pp. 73-89. DOI: 10.1002/ (SICI)1099-0909(199806)4:2<73::AID-DYS104>3.0.CO;2-\#

67. van den Bos K. P., Zijlstra B. J. H., \& van den Broeck W. Specific relations between alphanumeric-naming speed and reading speeds of monosyllabic and multisyllabic words. Applied Psycholinguistics, 2003, V. 24, Issue 3, pp. 407-430. DOI: 10.1017/S0142716403000213

68. Patel T. K., Snowling M. J., de Jong P. F. A Cross-Linguistic Comparison of Children Learning to Read in English and Dutch. Journal of Educational Psychology, 2004, V. 96 (4), pp. 785-797. DOI: 10.1037/0022-0663.96.4.785

69. Holopainen L., Ahonen T., \& Lyytinen H. Predicting Delay in Reading Achievement in a Highly Transparent Language. Journal of Learning Disabilities, 2001, V. 34, Issue 5, pp. 401-413. DOI: $10.1177 / 002221940103400502$

70. Korhonen T. T. The Persistence of Rapid Naming Problems in Children with Reading Disabilities: A Nine-Year Follow-Up. Journal of Learning Disabilities, 1995, V. 28, Issue 4, pp. 232-239. DOI: 10.1177/002221949502800405

71. Lepola J., Poskiparta E., Laakkonen E., \& Niemi P. Development of and Relationship Between Phonological and Motivational Processes and Naming Speed in Predicting Word Recognition in Grade 1. Scientific Studies of Reading, 2005, V. 9, Issue 4, pp. 367-399. DOI: 10.1207/s1532799xssr0904_3

72. Näslund J. C., Schneider W. Longitudinal effects of verbal ability, memory capacity, and phonological awareness on reading performance. European Journal of Psychology of Education, 1991, V. 6, pp. 375-392. DOI: 10.1007/BF03172772

73. Landerl K. Word recognition deficits in German: more evidence from a representative sample. Dyslexia, 2001, V. 7, Issue 4, pp. 183-196. DOI: 10.1002/dys.199

74. Mayringer H., Wimmer H. Pseudoname Learning by German-Speaking Children with Dyslexia: Evidence for a Phonological Learning Deficit. Journal of Experimental Child Psychology, 2000, V. 75, Issue 2, pp. 116-133. DOI: 10.1006/jecp.1999.2525

75. Wimmer $\mathrm{H}$. Characteristics of developmental dyslexia in a regular writing system. Applied Psycholinguistics, 1993, V. 14, Issue 1, pp. 1-33. DOI: $10.1017 /$ S0142716400010122 
76. Wimmer H., Mayringer H. \& Landerl K. Poor Reading: A Deficit in SkillAutomatization or a Phonological Deficit? Scientific Studies of Reading, 1998, V. 2, Issue 4, pp. 321-340. DOI: 10.1207/s1532799xssr0204_2

77. Clinton A. B. Phonology, orthography, and naming as predictors of reading ability in the Spanish language. Diss. Dr. Sci. Athens, GA, 2001. Available at: PQDT Open (Accessed 10 March 2018).

78. Novoa L. Word-retrieval process and reading acquisition and development in bilingual and monolingual children (Unpublished doctoral dissertation). Harvard University, Cambridge, MA, 1988. 231 p.

79. Chandarina A. S. Acquisition of Reading Skills in Russian-Speaking ESL Children. Diss. Dr. Sci. Toronto, ON, 2003. Available at: https://search.library. utoronto.ca/details?4783141\&uuid=79b1f28d-7ca1-460e-a7d7-b4c189fec793 (Accessed 10 March 2018).

80. Wolf M., O'Rourke A. G., Gidney C., Lovett M., Cirino P., Morris R. The second deficit: An investigation of the independence of phonological and naming-speed deficits in developmental dyslexia. Reading and Writing, 2002, V. 15, Issue 1-2, pp. 43-72. DOI: 10.1023/A:1013816320290

81. Mann V., Wimmer H. Phoneme awareness and pathways into literacy: A comparison of German and American children. Reading and Writing, 2002, V. 15, Issue 7-8, pp. 653-682. DOI: 10.1023/A:1020984704781

82. Chin C. E. The relations of phonological awareness and visual naming speed to beginning reading skills in at-risk children. Diss. Dr. Sci. Decatur, GA, 2001. Available at: PQDT Open (Accessed 10 March 2018).

83. Neuhaus G. F. An investigation of phonological awareness, orthographic recognition, and attention as predictors of rapid automatized naming (RAN) and reading. Diss. Dr. Sci. Houston, TX, 2000. Available at: PQDT Open (Accessed 10 March 2018).

84. Torgesen J. K. \& Burgess S. R. Consistency of reading-related phonological processes throughout early childhood: Evidence from longitudinal, correlational and instructional studies. In: J. Metsala \& L. Ehri (eds.) Word processing in beginning literacy. Mahwah, NJ, Erlbaum, 1998, pp. 161-188.

85. Wagner R. K., Torgesen J. K., Rashotte C. A. Development of readingrelated phonological processing abilities: New evidence of bidirectional causality from a latent variable longitudinal study. Developmental Psychology, 1994, V. 30 (1), pp. 73-87. DOI: 10.1037/0012-1649.30.1.73

86. Bishop A. G. Prediction of First-Grade Reading Achievement: A Comparison of Fall and Winter Kindergarten Screenings. Learning Disability Quarterly, 2003, V. 26, Issue 3, pp. 189-200. DOI: 10.2307/1593651

87. Dyer A., MacSweeny M., Szczerbinski M., Green L., Campbell R. Predictors of Reading Delay in Deaf Adolescents: The Relative Contributions of Rapid Automatized Naming Speed and Phonological Awareness and Decoding. 


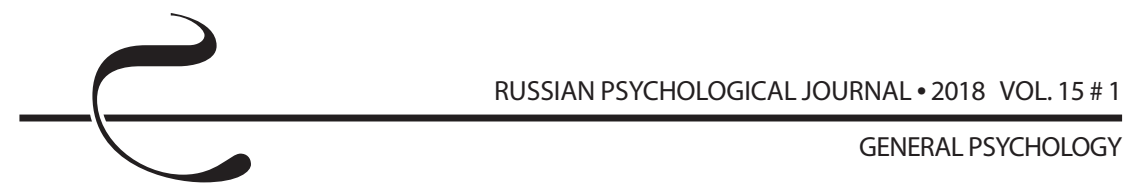

Journal of Deaf Studies and Deaf Education, 2003, V. 8, Issue 3, pp. 215-229. DOI: 10.1093/deafed/eng012

88. Holland J., McIntosh D., Huffman L. The Role of Phonological Awareness, Rapid Automatized Naming, and Orthographic Processing in Word Reading. Journal of Psychoeducational Assessment, 2004, V. 22, Issue 3, pp. 233-260. DOI: $10.1177 / 073428290402200304$

89. Torgesen J. K., Wagner R. K., Rashotte C. A., Burgess C. \& Hecht S. Contributions of Phonological Awareness and Rapid Automatic Naming Ability to the Growth of Word-Reading Skills in Second-to Fifth-Grade Children. Scientific Studies of Reading, 1997, V. 1, Issue 2, pp. 161-185. DOI: 10.1207/s1532799xssr0102_4

90. James J. S. Phonological processing in early reading and invented spelling. Diss. Dr. Sci. Kingston, ON, 1996. Available at: PQDT Open (Accessed 10 March 2018).

91. Kirby J. R., Martinussen R., \& Beggs P. Causal Path Analysis of Processes Affecting Early Reading. Canada; Ontario, American Psychological Association, 1996. Available at: https://files.eric.ed.gov/fulltext/ED407661.pdf (Accessed 10 March 2018).

92. Savage R. Motor skills, automaticity and developmental dyslexia: A review of the research literature. Reading and Writing: An Interdisciplinary Journal, 2004, V. 17, Issue 3, pp. 301-324. DOI: 10.1023/B:READ.0000017688.67137.80

93. Bowers P. G., Swanson L. B. Naming speed deficits in reading disability: Multiple measures of a singular process. Journal of Experimental Child Psychology, 1991, V. 51, Issue 2, pp. 195-219. DOI: 10.1016/0022-0965(91)90032-N

94. Deutsch G. K., Dougherty R. F., Bammer R., Siok W. T., Gabrieli J. D. E., \& Wandell B. Children's Reading Performance is Correlated with White Matter Structure Measured by Diffusion Tensor Imaging. Cortex, 2005, V. 41, Issue 3, pp. 354-363. DOI: 10.1016/S0010-9452(08)70272-7

95. Berninger V. W., Yates C., Lester K. Multiple orthographic codes in reading and writing acquisition. Reading and Writing, 1991, V. 3, Issue 2, pp. 115-149. DOI: 10.1007/BF00420030

96. Hammill D. D. What We Know About Correlates of Reading. Exceptional Children, 2004, V. 70 (4), pp. 453-469. DOI: 10.1177/001440290407000405

97. Swanson H. L., Trainin G., Necoechea D. M., Hammill D. D. Rapid Naming, Phonological Awareness, and Reading: A Meta-Analysis of the Correlation Evidence. Review of Educational Research, 2003, V. 73, Issue 4, pp. 407-440. DOI: $10.3102 / 00346543073004407$

98. Young A., \& Greig Bowers P. Individual Difference and Text Difficulty Determinants of Reading Fluency and Expressiveness. Journal of Experimental Child Psychology, 1995, V.60, Issue 3, pp. 428-454. DOI: 10.1006/jecp.1995.1048 
99. Denckla M. B., Cutting L. E. History and significance of rapid automatized naming. Annals of Dyslexia, 1999, V. 49, pp. 29-42. DOI: 10.1007/s11881999-0018-9

100. Savage R. S., Frederickson N., Goodwin R., Patni U., Smith N., Tuersley L. Relationships Among Rapid Digit Naming, Phonological Processing, Motor Automaticity, and Speech Perception in Poor, Average, and Good Readers and Spellers. Journal of Learning Disabilities, 2005, V. 38, Issue 1, pp. 12-28. DOI: 10.1177/00222194050380010201

101. Borenstein M., Hedges L., Higgins J., \& Rothstein H. Introduction to metaanalysis. Chichester, UK, Wiley, 2009. 421 p.

102. Cooper H. Research synthesis and meta-analysis: A step-by-step approach (5th ed.). Los Angeles, CA, SAGE Publications, 2017.360 p.

103. Bernard R. M., Borokhovski E., Schmid R. F., Tamim R. M., Abrami P. C. A metaanalysis of blended learning and technology use in higher education: From the general to the applied. Journal of Computing in Higher Education, 2014, V. 26, Issue 1, pp. 87-122. DOI: 10.1007/s12528-013-9077-3

104. Borokhovski E. F., Bernard R. M. Quantitative syntheses in social sciences: Methodology and practice of meta-analysis. Part 2. Psikhologiya. Ekonomika. Pravo - Psychology-Economics-Law, 2013, no. 3, pp. 41-56.

105. Borokhovski E. F., Bernard R. M. Quantitative syntheses in social sciences: Methodology and practice of meta-analysis. Part 1. Psikhologiya. Ekonomika. Pravo - Psychology-Economics-Law, 2013, no. 2, pp. 6-15 (in Russian).

106. Rosenthal R. Parametric measures of effect size. In: H. Cooper \& L. V. Hedges (eds.) Handbook of research synthesis. New York, NY, Russell Sage Foundation, 1994, pp. 231-244.

107. Borenstein M., Hedges L., Higgins J., Rothstein H. Comprehensive Metaanalysis Version 2. Biostat, Englewood NJ, 2005.

108. Hedges L. V., \& Olkin I. Statistical Methods for Meta-analysis. Boston, MA, Academic Press, 1985. 373 p.

109. Borokhovski E. Explorations of the rapid automated naming (RAN) task: What should the "A" in RAN stand for? (Unpublished doctoral dissertation). Concordia University, Montreal, QC, 2007. 330 p. Available at: https:// spectrum.library.concordia.ca/975691/1/NR31121.pdf (Accessed 25 February 2018).

110. Stringer R.W., Toplak M. E., Stanovich K. E. Differential relationships between RAN performance, behavioral ratings, and executive function measures: Searching for a double dissociation. Reading and Writing, 2004, V. 17, Issue 9, pp. 891-914. DOI: 10.1007/s11145-004-2770-x 